\title{
Electrical Energy Demand in Rural India - A Case Study of Arunachal Pradesh and Uttar Pradesh
}

\author{
Anna-Kaarina Seppälä ${ }^{1, *}$, Nabin Raj Gaihre ${ }^{1}$, and Rinald Pereira ${ }^{1}$ \\ ${ }^{1}$ Chair of Renewable and Sustainable Energy Systems, Technical University of Munich, Munich, Germany
}

\begin{abstract}
India currently has the biggest unelectrified population in the world. Renewable-based microgrids could provide a sustainable solution to providing universal energy access. However, the potential electricity demand in rural areas is unknown and hard to predict. This data is needed to analyse the purchasing power and potential market for microgrids, and to assess their success rate. This study surveyed 73 households in Arunachal Pradesh and Uttar Pradesh in India, to study the energy need in rural communities. The data shows that many unelectrified households are already using electrical appliances powered by small photovoltaic panels or batteries. The consumption is not income-generating but potential productive use cases are widely present. In Uttar Pradesh, small-scale microgrids are already providing homes with enough power for lighting and mobile chargers. An average unelectrified household was found to consume $2.48 \mathrm{kWhe}$ monthly, and to spend ₹ 155 on energy services. Villagers wish for more appliances and more power, and have the required finances to pay for it.
\end{abstract}

\section{Introduction}

Climate change causes rising temperatures and extreme weather events such as droughts, storms and flooding [1]. Millions of people in emerging nations, are put at risk directly or due to loss of livelihood. Severe measures are needed to stop the production of green-house gases (GHS) but the global energy consumption is rapidly increasing [2]. In developed countries, the per-capita energy usage is on the rise [3], and in countries such as India and China, a middle class with Western consumption patterns has emerged, followed by a vast rural population whose socio-economic development depends on energy access [4]. The growing demand must be satisfied in a sustainable manner to minimise the global warming effects of power production whilst providing universal access to clean energy.

India has 240 million inhabitants without access to electricity [5], at least one third of whom live in rural areas, out of reach of the national grid [6]. Due to difficult terrain and high cost, grid extension to these villages is unlikely in the foreseeable future. Further, the government of India is claiming 100 per cent electricity access as of April 2018, potentially leading to cuts in funding for electrification schemes [7].

In remote locations, small off-grid systems could provide a reliable and cost-effective power source and improve the quality of life of rural populations. Utilising renewable re-sources would minimise negative effects on the climate and provide health benefits as opposed to conventional fuels [6]. The decentralised nature of offgrid systems would reduce the cost of electricity in absence of transmission infrastructure and transmission losses.

To design and size off-grid systems, it is necessary to assess the current and future energy need of the targeted communities, and their financial status and purchasing power. The lack of data on energy demand and appliance usage patterns in remote areas is a major obstacle to providing universal access to sustainable power.

In this study, multiple villages of varying stages of electrification in Arunachal Pradesh and Uttar Pradesh were surveyed. The aim was to determine the energy need across two demographically very different states and to provide an overview of the possibilities for standalone microgrids in these regions. The focus was on nonelectrified villages but partially and fully electrified communities were included as a reference. The survey consisted of three questionnaires, one aimed at households, one at village heads and one specifically for schools. The study was conducted be-tween May and July 2018.

\subsection{Arunachal Pradesh}

With 13 people/sq.km, Arunachal Pradesh (AP) has the lowest population density of all states of India [8]. Due to its few inhabitants, mountainous terrain, extending the national grid to AP is strenuous and expensive, and has thus largely been neglected.

The state has a huge hydropower potential that to this day has failed to provide electricity locally [9]. The demanding terrain makes transport within AP extremely difficult. Only few paved roads exist and landslides are com-mon in the mountains. The local economy is based

Corresponding author: anna.seppaelae@tum.de 
on agriculture and the manufacturing sector is limited [10]. Thanks to the abundance of water, irrigation is mostly not needed.

\subsection{Uttar Pradesh}

Uttar Pradesh (UP), with almost 200 million inhabitants, is the most populous state in India [11], [12]. Its geography is marked by vast plains of the Ganges River. The state suffers from a dire electricity shortage and a low adoption rate for connections even when the grid would be available [6]. Electricity access growth in UP has failed to keep pace with population growth.

UP's main source of income is agriculture based on seasonal crops such as rice, wheat and sugarcane. Thanks to UP's more developed transport infrastructure, farmers have better access to fertilisers and modern irrigation technologies [11]. In the dry season, temperatures up to 50 centigrade are reached and irrigation becomes essential. Figure 1 shows both states on the map.

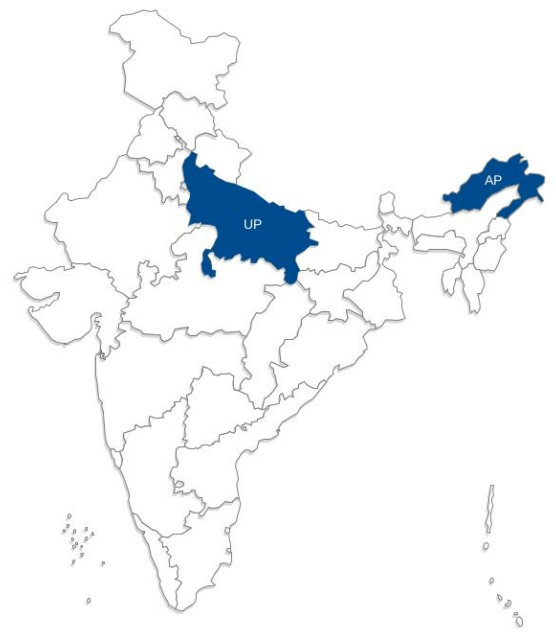

Fig. 1. Uttar Pradesh (UP) and Arunachal Pradesh on the map [13].

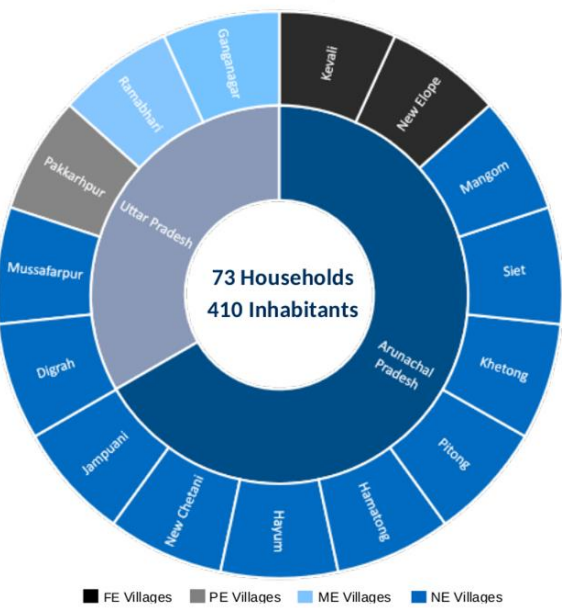

Fig. 2. Overview of surveyed villages and their electrification status.

\section{Method}

Two categories of electrical energy consumption were defined; consumptive usage and productive usage. The former comprises all use contributing to improved comfort within a household but not helping to generate income. The latter entails use cases promoting economic activities [14]. Thus, it also comprises endeavours improving education and health because both have positive implications on income [15].

The presence of productive use cases is linked to communities' ability to pay for or maintain off-grid power systems. Both categories may be extended by energy demand that could be covered by electricity in the future. Hence, if a village has an active workshop where all mechanical repairs are currently done manually, it is probable that the workers will adopt electrical machinery when power becomes available. Such a scenario makes building an off-grid system more viable than one where only consumptive use patterns are present.

To understand consumptive and productive electricity demand, and assess possible future trends, a survey was created and subsequently carried out in Indian villages of various degrees of electrification.

\subsection{Survey Coverage}

AP and UP were chosen as the study sites for their low electrification rate, the remote location of villages and, in the case of AP, the challenging terrain. It is improbable that the surveyed communities would receive access to the national grid in the foreseeable future. Further, the differences in terms of the geographical and socioeconomical characteristics of the two states guarantees a more general view oft he electricity demand in India. In total, 73 households in 15 villages across AP and UP were surveyed, with 10 in the former and 5 in the latter. The total population covered by the study was 410 . Additionally, one non-electrified govern-mental residential school in AP was included in the survey. The visited villages may be organised into four different categories according to their level of electrification: Nonelectrified (NE), microgrid electrified (ME), partially electrified (PE) and fully electrified (FE). Villages with no access to the national grid nor microgrids were deemed non-electrified, although some households may own private solar installations. 10 such villages were surveyed. Figure 2 provides an overview. 


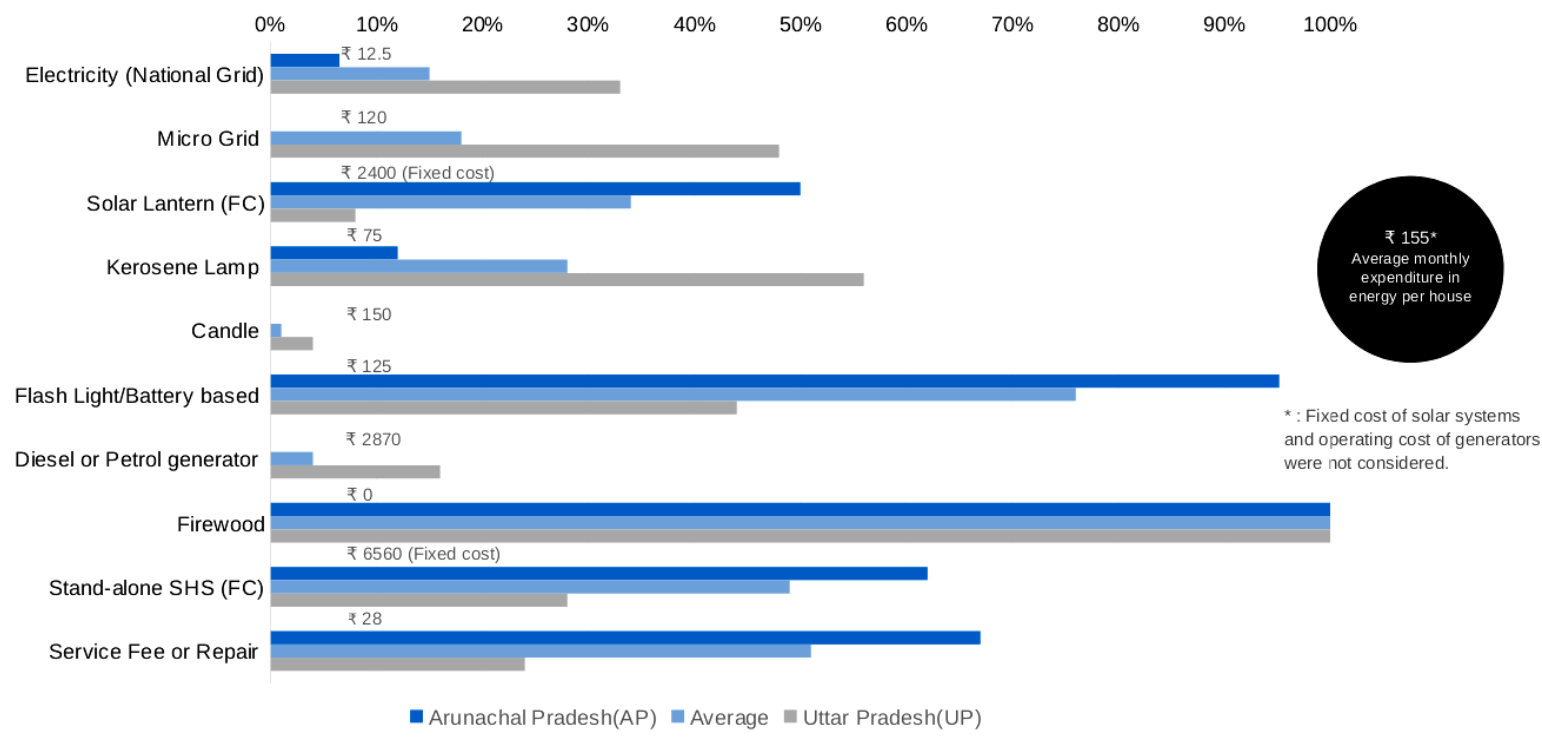

Fig. 3. Current energy access situation across all surveyed households in AP and UP. Average monthly expenditure per household on each energy source is also shown.

Two microgrid electrified villages were included in the survey. Typically these villages have tier 1 electricity access $^{\text {a }}$ provided by a microgrid company. The visited ME locations have been provided electricity access by the company Mera Gao Power ${ }^{b}$. Partially electrified villages are those connected to the national grid but without regular access to electricity. Power only becomes available if there is surplus in the grid. One such location in UP was surveyed, but additionally, two mainly NE villages were found to have individual PE households.

Further, two fully electrified villages were visited. FE communities have regular access to electricity via the national grid, and the power capacity exceeds that of tier 3 [6]. No microgrid-powered village made it into the FE category as their power capacity was found to be insufficient for a fully electrified status.

$\mathrm{PE}$ and FE villages were included in this study to provide a reference for energy need and were chosen in the vicinity of the unelectrified communities visited. Surveying villages with similar cultural and demographic characteristics allowed for a better estimate of the future trends in energy use in communities new to electricity access. Additionally, the governmental residential school in Jamupani, AP, was surveyed for its significant impact on the village economy, and because it represents additional productive use case for electricity. Schools in other communities were closed at the time of the survey, and their productive use cases were assumed to be similar to Jamupani.

\section{Results}

\footnotetext{
a According to the definition of the World Bank, tier 1 electrification corresponds to households with access to very low power (minimum $3 \mathrm{~W}$ ) for atleast 4 hours per day [16]. ${ }^{\mathrm{b}}$ Mera Gao Power have provided each household in the surveyed villages with a $7 \mathrm{~W}$ connection that allows them to power $1 \mathrm{~W}$ LED lamps and a mobile phone charger.
}

In AP, 94 per cent of the surveyed households were found to do sustenance farming, relying on cash crops such as cardamom, yam or opium for extra income. 15 per cent of interviewees also do other manual labour such as headloading goods. In UP, 42 per cent of surveyees in UP were employed as labourers and 63 per cent cultivated seasonal crops like sugarcane, wheat or maize for their income. These categories overlap as some households have multiple sources of earnings.

The average monthly income of the surveyed NE and ME households was ₹ 10,522 ( $€$ 124.9), resulting in an average per-capita annual income of ₹ 21,783 (€ 290.6). This value is 81 per cent less than the national average [17]. In AP, the average monthly income was found to be significantly higher (at ₹ 11,471 ) than in UP (₹ 8,269). This is mainly because of the high-value crops cultivated in AP.

\subsection{Access to energy}

$\mathrm{NE}$ and $\mathrm{ME}$ communities rely heavily on alternative sources for light and electricity. These include kerosene lamps, batteries, firewood, solar home systems (SHS) and solar lanterns. Especially in AP, solar-home systems and electric torches are immensely popular, with 62 and 95 percent of the households using them, respectively. In UP, the corresponding figures were 28 and 44 per cent. Instead of torches, many UP households were using the flashlight application on their mobile phones. Every household was found to use firewood on a day-to-day basis. Figure 3 shows the percentage of all surveyed households with access to various energy sources. The AP and UP-wide average expenditure on these sources is also given. It is immediately clear that the monthly expenditure on a grid connection seems very low compared to microgrid-based electricity. This, however, is an artefact of most PE households neglecting the payment of the fee. In AP, households pay between ₹ 120-180 for the grid, and in UP all except one household 


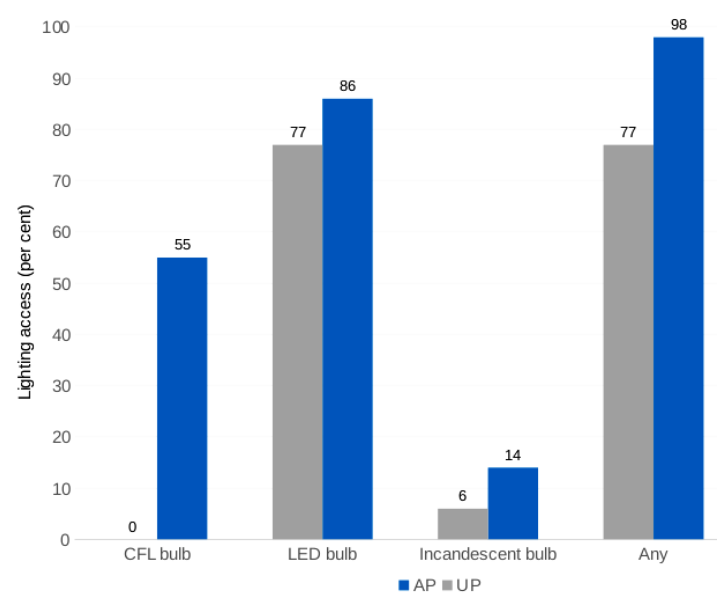

Fig. 4. The variation in access to lighting in ME and NE households across AP and UP.

were reported to ignore their electricity bill. According to the interviewees, the reliability of the provided power was so bad that they did not consider it worth paying for. The only household paying for grid connection gave a figure of ₹ 100 as the price per month. For comparison, the microgrid operator Mera Gao Power charges its customers ₹ 120 a month for electricity.

The average monthly amount spent on consumptive energy services was ₹ 155 across all surveyed households. In AP, households tend to pay more, resulting in an APonly average of ₹ 174 . Consequently, in UP the average is lower at ₹ 123 per month. Neither the fixed cost for solar systems nor the operating cost of diesel and petrol generators were considered in these average values. The generator operating cost was neglected mainly to compare consumptive energy expenditure between AP and UP.

\subsection{Consumptive electrical energy demand}

98 per cent of the surveyed ME and NE households own electrical appliances even though not all were able to use them due to shortage in power. Figure 4 shows access to different types of light bulbs in AP and UP, whereas household access to other appliances is depicted in figure 5. All the depicted appliances, lighting and otherwise, represent consumptive usage.

In AP, households typically have more than one type of lighting source and 98 per cent of homes had access to at least one. In UP, 77 per cent of households have access to lighting via electric bulbs, and they effectively only use LED bulbs. This is largely due to microgrid operators such as Mera Gao Power that provide LED's as part of their microgrid solutions.

Despite their remote location, households in AP have more televisions, with 41 per cent of interviewees owning at least one. The corresponding figure for UP is a mere 6 per cent. Owning a TV set, however, does not directly imply higher consumption rates as many households

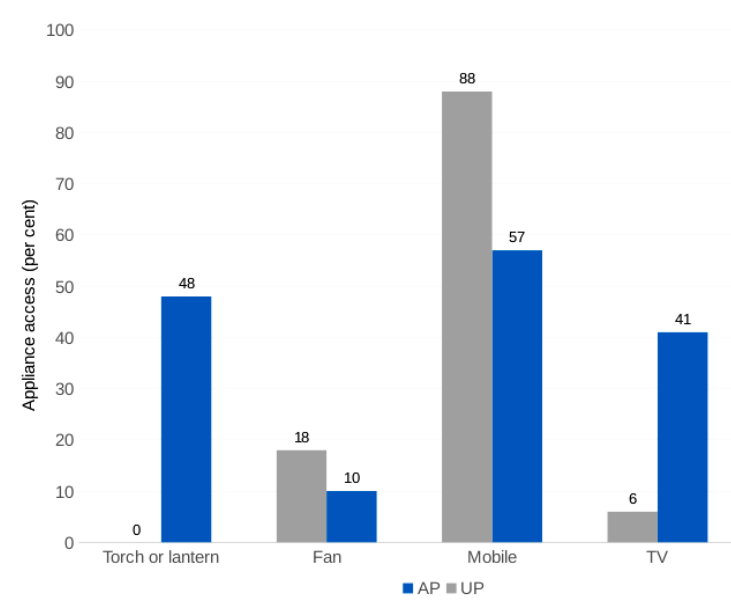

Fig. 5. Access to common household appliances in $\mathrm{AP}$ and UP.

complained that they do not receive enough power to use their televisions as often as they would like ${ }^{c}$.

ME and NE households in AP were shown to have improved access to a variety of appliances compared to those in UP. The higher income in the former thus seems to dominate over remoteness and transport infrastructure. Other factors affecting appliance usage in AP and UP include differences in climate; The fact that fans are more widely found in UP is naturally due to higher temperatures and increased cooling need.

It must also be mentioned that the Government of India reached out to many of the surveyed villages in AP in the early 1990 's, drawing lines to connect them to the national grid, and giving them incandescent lights. However, according to the interviewees, they never actually received electricity. At present, the lines have fallen into decay, having never been used. Consequently, even though some households in AP own incandescent lights, none actually uses them as they are connected to the old non-functional lines.

To summarise, all electrical appliances used in AP and UP currently fit into the category of consumptive loads as defined in section 2 . The following section gives an over view of the current and potential productive use cases in the two states.

Household electricity consumption was determined based on user evaluation of daily usage duration for all electrical appliances. The variation in average monthly consumption in AP and UP is presented in figure 6. The monthly electricity consumption was found to be 2.73 times greater in Arunachal compared with UP. This clearly reflects the higher socio-economic status of the households in AP, and correlates with their improved access to electrical appliances. The electrical energy consumption averaged over all visited $\mathrm{NE}$ and $\mathrm{ME}$ communities is a mere $2.48 \mathrm{kWh}$ per month per household. This is almost 21 times less than the consumption in the surveyed FE households, and extremely low compared to Western countries. For the

\footnotetext{
${ }^{c} 50$ per cent of all TV owners in ME and NE households reported they never use it.
} 
sake of comparison, the average U.S. residential utility customer consumes $897 \mathrm{kWh}$ per month [18].

As seen from figure 7, the largest electrical load consists of the combination of TV and setup box (set-top unit), closely followed by the combined lighting load of LED's, CFL bulbs and lanterns (torches).

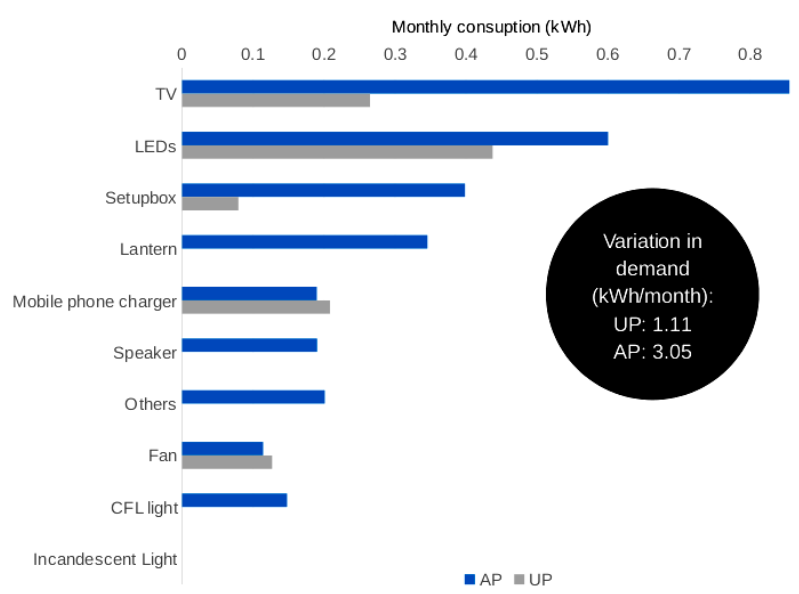

Fig. 6. The average monthly household consumption by appliance in AP and UP.

\subsection{Productive use of energy}

Little of the current energy demand in AP or UP can be regarded as productive use of energy. Apart from seasonal usage of water pumps, no productive loads were found. Both states were still found to offer potential productive use cases provided enough power is available. Promising possible productive use cases in Arunachal Pradesh are weaving, carpentry, drying and packaging of cash crops, and street lights. Especially weaving of traditional dresses could be very affordable, and one household in AP reported a monthly income of ₹ 1,500. At the moment, weaving may only be carried out during daytime, when most villagers are out on their fields. With lighting, this activity could be extended to evening and the potential income increased.

In AP, houses and furniture are mostly made of bamboo and wood, and with electric power tools carpentry could be made more viable a profession. According to the survey, 11 per cent of households expressed interest in this type of machinery. Most of AP's cash crops are currently dried naturally, which in the humid climate is very slow and may lead to rotting. If enough power was available, this could be done by means of electricity.

In Uttar Pradesh, irrigation pumps are the most obvious productive use case, and the only one villagers are actively spending money on at present. All farmers require irrigation during the dry season, and spend ₹ 2,870 per month, on average, on diesel or petrol to operate the pumps. 12 percent of surveyed households own their own water pump and the rest are paying to use one. Provided reliable electricity access, electrical pumps would be a far more economical solution. These could be grid-powered or solar-based.

\subsection{School survey outcome}

The surveyed governmental residential school in Jamupani teaches from year one to year eight, and around 50 children from Jamupani and neighbouring villages stay there nine months a year, along with 10 staff members. Most children in the region attend the school,

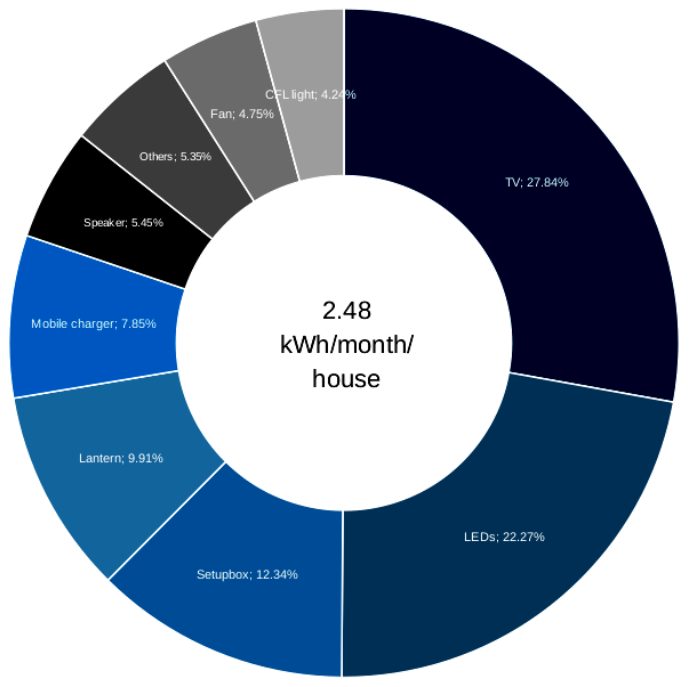

Fig. 7. Average consumption across all NE and ME households in the survey.

in part thanks to the government of AP offering two free meals per day, which is a substantial help for many households. Also, the fact that tuition is free of charge is a major contributing factor. Currently, the only source of electricity at Jamupani school are small, privately acquired photovoltaic panels that power eight 3-watt LED bulbs for about four hours per day. Cooking is done with firewood that the pupils gather in the nearby forest. The lack of electricity is a major problem for security as children have to navigate to outside toilets after dark, and also for the educational aspect as studying becomes impossible after sundown. At present, the school is unable to fulfil some requirements of the national curriculum as they do not have TV sets.

\subsection{Purchasing power and future outlook}

Almost every surveyed ME/NE household in AP and UP showed interest in buying more appliances or increasing the usage of old ones provided enough power would be available. 85 percent of households wished to either acquire a TV set or watch it more often, putting it at the top of their wish list as shown in figure 8. Also, the headmaster of Jamupani school in Arunachal reported hoping for more appliances.

The survey data shows that ME and NE households spend more money (₹ 155 per month) on electricity than FE villages (₹ 130 per month). This is surprising due to the limited electricity access in ME and NE communities. For an electrical load 21 times smaller than that of FE households, ME and NE homes spend 19 per cent more on electricity. Fully electrified households pay a monthly connection fee whereas non-electrified and microgrid 
electrified homes need to buy batteries, candles, kerosene and petrol.

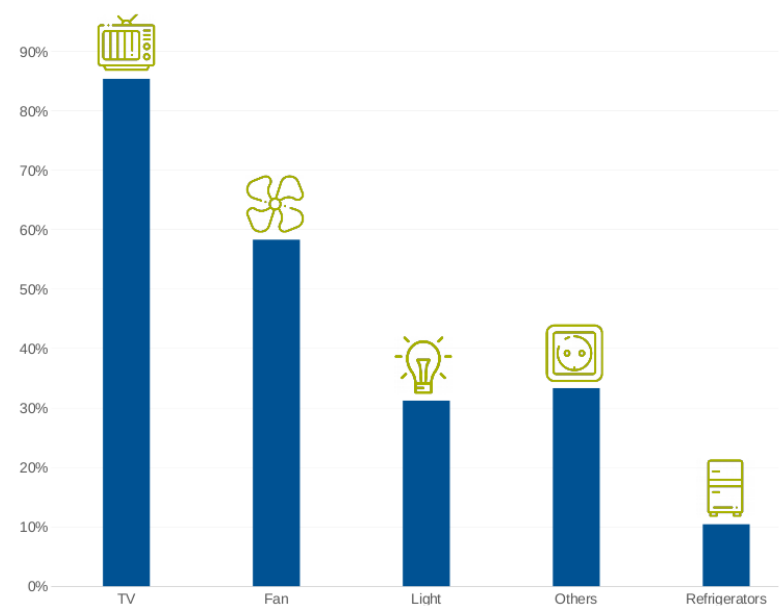

Fig. 8. Percentage of ME and NE households wishing to buy an appliance or to extend its usage. Smartart from [19].
AP
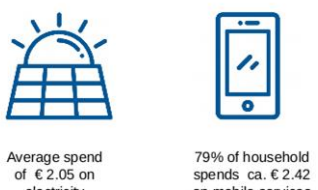
on mobile services
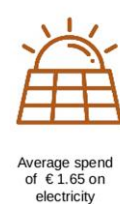

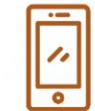

$79 \%$ of household
spends ca. $€ 1.42$
on mobile services

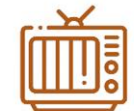

$7 \%$ of household
spends ca.e1.18
Fig. 9. Comparison of average monthly expenditure on energy services in AP and UP. Smartart from [19].

When asked, those households in AP willing to pay for extra electricity were ready to give an average of ₹ 179 per month. In UP, this figure was even higher at ₹ 193, regardless of their lower monthly income. This is very probably due to the fact that UP households already have a productive use case (water pumping) in place, and know that more reliable electricity is directly related to higher income. In Arunachal Pradesh, the villagers tend to regard electricity purely as an added comfort in the home.

In figure 9 , an overview of average monthly expenditure on energy in both AP and UP is given.

\section{Conclusion}

From the survey results it is clear that non-electrified villages and villages with minimal electricity access provided by small-scale microgrids are willing and able to pay for improved energy services. The comparison with FE villages shows that with electricity access, the monthly consumption might rise to over 20 times its current level. Also, both AP and UP have an abundance of possible productive use cases that could help improve the socio-economic status of the surveyed villages if they are provided a reliable power supply. This would provide a further incentive for microgrid companies.

The double-layered survey strategy was used in this study in order to improve the trustworthiness of the results. Village stakeholders were found to be more open about the illegal income sources within the community than household members directly involved in these activities. Regarding error in reported consumption patterns, each surveyed house hold was examined to find all electrical appliances and their power capacities were noted down. Appliance usage patterns were compared within and across communities to ensure data homogeneity. The results found in this study may readily be used to evaluate the feasibility of microgrids providing higher tier electrification in AP and UP. Communities are clearly interested and willing to pay for such services, and productive use cases are abundant.

The research team would sincerely like to thank Merwyn Coutinho, Hrishikesh Chowdhury and Anjite Menjo of Further and Beyond, Nikhil Jaisinghani, Sandeep Pandey and Vijyender Shukla of Mera Gao Power, and Professor Pinak Mahanta and Sachankar Buragohain from IIT Guwahati. This research was partly funded by Maj and Tor Nessling Foundation.

\section{References}

1. M. Monirul Qader Mirza, June 15th, 2011, Climate change and extreme weather events: can developing countries adapt?, Climate Policy, 3233.

2. British Petrol, June 2018, BP Statistical Review of World Energy, London.

3. Statista, 2018, U.S. total energy consumption from 1975 to 2018, by sector, retrieved September 6th, 2018 , from https://www.statista.com/statistics/239790/totalenergy-consumption-in-the-united-states-by-sector/

4. J. Sumanik-Leary, M. Delor, M. Little, M. Bellamy, A. Williams, S. Willimason, 2014, Engineering in Development - Energy, London, Engineers Without Borders UK.

5. R. Kumar Singh, S. Sundria, January 24th, 2017, Living in the Dark: 240 Million Indians Have no Electricity, Bloomberg, retrieved September 8th, 2018, from https://www.bloomberg.com/news/features/20170124/living-in-the-dark-240-million-indians-haveno-electricity

6. S. Ghosh, D. Barnes, B. Singh, K. Mayer, H. Samad, 2015, Power for All: Electricity Access Challenge in India, Washington DC, World Bank Studies.

7. Sanjay Dutta, April 29th, 2018, Mission Accomplished: PM Narendra Modi gives power to all 19,000 unelectrified villages, The Times of India.

8. Smart Power India, May 2017, Smart Power Connect, 2

9. R. Bhoi, S. Ali, April 2014, Potential of Hydro Power in India and its Impacts on Environment, IJETT, 10114. 
10. D. Lodrick, 2018, Encyclopaedia Britannica Arunachal Pradesh, retrieved September 6th, 2018, from https://www.britannica.com/place/ArunachalPradesh

11. R. Mathur, 2018, Encyclopaedia Britannica - Uttar Pradesh, retrieved September 6th, 2018, from https://www.britannica.com/place/Uttar-Pradesh

12. Government of Uttar Pradesh, 2017, Social Demography, retrieved on September 6th, 2018, from up.gov.in/Social-Demography.pdf

13. Your Free Template, retrieved August 2018, from: https://yourfreetemplates.com/india-map-blanktemplates/

14. R. White, 18th June, 2002, GEF-FAO Workshop on Productive Uses of Renewable Energy: Experience, Strategies, and Project Development, Workshop Synth. Rep., UNFood Agric. Organ., Rome, Italy
15. R. Anil Cabraal et. al., 2005, Productive Use of Energy for Rural Development, Annu. Rev. Environ. Resour., 30117.

16. The World Bank ESMAP Programme, 2015, Beyond Connections - Energy Access Redefined.

17. The Times of India, India's per capita income grows by $8.6 \%$ to Rs 1.13 lakh in FY18, retrieved August, 2018, from https://timesofindia.indiatimes.com/business/indiabusiness/indias-per-capita-income-grows-by-8-6-tors-1-13-lakh-in-fy18/articleshow/64403580.cms

18. U.S. Energy Information Administration, How much electricity does an American home use?, retrieved December 27, 2017, from https://www.eia.gov/tools/faqs/faq.php?id=97\&t=3

19. Freepik Company S.L., Flaticon free vector images, retrieved September 1st, 2018, from https://www.flaticon.com 